\title{
Chemical and electrochemical corrosion of a copper alloy in aqueous solutions by using Morus Alba extract as an eco-friendly inhibitor
}

\author{
A.S. Fouda, ${ }_{\oplus} *$ S.E. Badr, ${ }^{2}$ A.M. Ahmed ${ }^{2}$ and A. El-Hossiany ${ }^{1,3}$ \\ ${ }^{1}$ Chemistry Department, Faculty of Science, El-Mansoura University, Mansoura-35516, \\ Egypt \\ ${ }^{2}$ Chemistry Department, Faculty of Science, Alexandria University, Alex-21568, Egypt \\ ${ }^{3}$ Delta for Fertilizers and chemical industries, Talkha, Egypt \\ *E-mail: asfouda@hotmail.com
}

\begin{abstract}
Morus Alba extract was studied as the corrosion inhibitor for copper $(\mathrm{Cu})$ in 2 molar $\mathrm{HNO}_{3}$ utilizing chemical and electrochemical tests. From chemical tests, one can observe that with increasing doses of Morus Alba extract up to $300 \mathrm{ppm}$ the inhibition efficacy was increased to 93.2\% (after 3 hours) at $25^{\circ} \mathrm{C}$. The adsorption of Morus Alba extract on $\mathrm{Cu}$ surface follows the Flory-Huggins adsorption isotherm. The inhibition efficacy increases with increasing the dose of the Morus Alba extract and decreases with rise in temperature of the medium. This extract may form a film which acts as a barrier, to minimize the contact area between copper surface and $\mathrm{HNO}_{3}$ solution. Morus Alba extract acts as mixed type of inhibitor in $\mathrm{HNO}_{3}$ solution without any change in the mechanism of the process. From the EIS examination, we notice the decrease in the values of double layer by increasing the dose of Morus Alba extract, on the other hand, the charge transfer resistance is increased. Thermodynamic parameters of activation and adsorption processes were calculated and discussed that the sign of the free energy of adsorption showed spontaneous process of adsorption. The surface morphology of copper metal was examined by employing various techniques. Results are in good harmony for all techniques used.
\end{abstract}

Received: July 5, 2021. Published: August 7, 2021

doi: $\underline{10.17675 / 2305-6894-2021-10-3-12}$

Keywords: Morus Alba extract, corrosion inhibition, copper, nitric acid, Flory-Huggins isotherm, potentiodynamic polarization.

\section{Introduction}

Corrosion is an electrochemical process that occurs in the presence of an electrical current. Copper has been one of the most widely utilized metals for industrial and residential purposes because of its outstanding electrical conductivity, strong mechanical workability, low cost, and other relatively noble qualities. A range of environmental reasons can easily cause the corrosion of copper. Nitric acid is the most widely utilized corrosive solution for copper, so, many researchers deals with it as corrosive solution for copper [1-3]. The use of 
inhibitors is the most practical method for defending against the successive dissolution of metal by corrosion. The use of $\mathrm{O}, \mathrm{S}$ and $\mathrm{N}$-containing organic compounds to minimize metal corrosion has been studied [4-10]. The presence of hetero atoms in the inhibitor's chemical structure plays a significant role in the action of corrosion inhibition. Other factors have a significant influence on the efficiency of inhibition, such as molecular weight, aromatic rings, and inhibited metal load [11-15]. Since obtaining synthetic organic inhibitors is costly in addition to environmental damage, researchers have recently focused their efforts on replacing synthetic organic inhibitors with inhibitors that can be obtained from natural materials. Naturally, occurring corrosion inhibitors are environmentally friendly, available, inexpensive, and sources for obtaining them are renewable [16-18].

The main objective of this work was to examine the inhibitive property of Morus Alba extract towards the corrosion of copper in $2 \mathrm{M} \mathrm{HNO}_{3}$ solution and to analyze its surface.

\section{Experimental Methods}

\section{Materials and solution}

$2 \mathrm{M}$ nitric acid $\left(\mathrm{HNO}_{3}\right)$ was prepared in the laboratory by diluting the appropriate volume of analytical grade, $69 \% \mathrm{HNO}_{3}$ with double distilled water. The samples of copper were cut out from a copper sheet with chemical composition (wt.\%) 1.055 Si, 4.248 Mn, 1.832 Zn and the remains is copper. For chemical tests, the size of copper samples was $20 \times 20 \times 2 \mathrm{~mm}$ and for electrochemical measurements was $10 \times 10 \mathrm{~mm}$ Prior to the assessment, the samples were abraded with various grades of emery papers (250-3000) till mirror finish.

\section{Preparation of the Morus Alba extract (inhibitor)}

The present investigation was carried out using a plant, namely Morus Alba. The samples were collected from the Morus Alba plant and ground into a fine powder to give $500 \mathrm{~g}$ of powdered materials, a known quantity of the materials was Soxhlet using double distilled water. Finally, the extract was dried out, weighed, and preserved at $5^{\circ} \mathrm{C}$ and kept for the use when required. Morus Alba have contains antioxidant components, which includes rutin, isoquercitrin, astragalin and quercetin-3-(6-malonyl)glucoside among which quercetin-3-(6malonyl)glucoside, quercetin3- $O$ - $\beta$-glucopyranoside-7- $O$ - $\alpha$-rhamnopyranoside, kaempferol7-O-glucoside, anthraquinones, flavonoids, polyphenols lipids, sterols and quercetin-3-Orhamnopyranoside-7-O-glucopyranoside are most abundant in dried extract [19]. Different doses were prepared from the stock solution besides the control and were tested for their anticorrosion effects.

\section{Mass loss (ML) method}

Copper specimens with dimensions of $(2.1 \times 2.0 \times 0.2) \mathrm{cm}$ were prepared, degreased with acetone, immersed in double distilled water, and dried using filter papers. Weight the specimens then immersed them in $100 \mathrm{~mL}$ of $2 \mathrm{M} \mathrm{HNO}_{3}$ with and without altered doses of Morus Alba extract at $25^{\circ} \mathrm{C}$. The copper samples were taken out after altered immersion 
periods, washed with double distilled water, dried and weighed again. The corrosion rate $(C R)$ in $\mathrm{mm} \mathrm{y}^{-1}$ was calculated from the ML value using Eq. (1):

$$
C R(\text { corrosion rate })=\Delta m / S t
$$

Mass reduction is $\Delta m$, the sample surface area exposed to the solution in $\mathrm{cm}^{2}$ expressed by $S$, and the submersion time as $t$ in min. \%IE, surface coverage $(\theta)$ utilizing the Eq. (2):

$$
\% I E=\theta \cdot 100=\left[\left(C R^{*}-C R\right) / C R^{*}\right] \cdot 100
$$

Where $C R^{*}$ and $C R$ are the corrosion rates of copper in the uninhibited and inhibited solution, correspondingly.

\section{Electrochemical measurements}

Electrochemical tests were performed using Gamry (Potentiostat/Galvanostat). The used cell is a three-electrodes electrochemical cell. The working electrode was prepared from copper sheet, mounted in polyester such that the area exposed to solution was $1 \mathrm{~cm}^{2}$. A platinum electrode, and a saturated calomel electrode (SCE) were used as counter and reference electrode, respectively. All potentials are reported vs. SCE. In the case of polarization tests, the potential changed from -600 to $+600 \mathrm{mV}$ and the potential sweep rate was $1 \mathrm{mV} / \mathrm{s}$. The dipped time before tests was $30 \mathrm{~min}$. Experiments are repeated three times to confirm them. The \% IE enabled for Morus Alba extract is as follows [20]:

$$
\begin{gathered}
\% \text { IE }=\left[\left(i_{\text {corr }}-i_{\text {corr(inh) })}\right) / i_{\text {corr }}\right] \cdot 100 \\
\theta=\left[\left(i_{\text {corr }}-i_{\text {corr(inh) })}\right) / i_{\text {corr }}\right]
\end{gathered}
$$

where $i_{\text {corr }}$ and $i_{\text {corr(inh) }}$ are the uninhibited and inhibited corrosion current density values, respectively, determined by extrapolation of both Tafel lines to the corrosion potential.

The EIS tests were performed in the frequency range of $100 \mathrm{kHz}$ to $0.1 \mathrm{~Hz}$, at the rest potential, by applying $10 \mathrm{mV}$ sine wave AC voltage. The double layer capacitance $\left(C_{\mathrm{dl}}\right)$ and the charge transfer resistance $\left(R_{\mathrm{ct}}\right)$ were computed from Nyquist plots as described before. The (\%IE) and the $(\theta)$ of the Morus Alba extract obtained from the EIS tests were calculated by applying the following relation Eq. (5):

$$
\% I E=\theta \cdot 100=\left[1-\left(R_{\mathrm{ct}}^{0} / R_{\mathrm{ct}}\right)\right]
$$

Where $R_{\mathrm{ct}}$ and $R_{\mathrm{ct}}^{0}$ are the charge transfer resistances for the inhibited system by Morus Alba extract and the inhibitor-free system from Morus Alba extract.

EFM experiments were performed with applying potential perturbation signal with amplitude $10 \mathrm{mV}$ with two sine waves of 2 and $5 \mathrm{~Hz}$. The choice for the frequencies of 2 and $5 \mathrm{~Hz}$ was based on three arguments. The larger peaks were used to calculate the corrosion current density $\left(i_{\text {corr }}\right)$, the Tafel slopes $\left(\beta_{\mathrm{c}}\right.$ and $\left.\beta_{\mathrm{a}}\right)$ and the causality factors CF 2 and CF3 [21]. 


\section{Surface morphology}

The copper surface was prepared by immersing the specimens for 24 hours in $2 \mathrm{M} \mathrm{HNO}_{3}$ attendance and lack optimum dose of Morus Alba extract, after abraded using different emery papers up to 3000 grit size. Then, the specimens were washed with double distilled water after this immersion period, carefully dried and mounted into the spectrometer. The corroded copper surfaces were examined using atomic force spectroscopy technique (AFM) was carried out in contact mode using a silicon nitride probe (MLCT model; Bruker) and a scanning electron microscope (SEM, JOEL, JSM-T20, Japan).

\section{Results and Discussion}

\section{ML measurements}

ML is one of the important methods in determining the efficiency of the inhibitor to inhibit the corrosion of $\mathrm{Cu}$ metal the experiments were conducted on altered dose of the Morus Alba extract in $2 \mathrm{M}$ nitric acid. The whole experience took three hours. Experiments were conducted at different temperatures $\left(25-40^{\circ} \mathrm{C}\right)$. Table 1 shows the results obtained in a time of 120 minutes as an example of the study. We find that by increasing the dose from $50 \mathrm{ppm}$ to $300 \mathrm{ppm}$, the rate of inhibition rises in contrast to the rate of corrosion, which decreases with increasing doses of Morus Alba extract. By increasing the temperature of the medium, the $\% I E$ will be decreased, while there is a direct correlation with temperature with corrosion rate (Figures 1 and 2). The increased \%IE with increased dose of Morus Alba extract can be attributed to the formation of a layer of the extract on the $\mathrm{Cu}$ surface by adsorption. This layer is formed by the pairs of free electrons present on the oxygen atoms in the Morus Alba extract molecules as well as the $\pi$-electrons of the aromatic rings [22].

Table 1. Data of ML of $\mathrm{Cu}$ in $2 \mathrm{M} \mathrm{HNO}_{3}$ solution for altered of Morus Alba extract after 120 min., at (25$\left.45^{\circ} \mathrm{C}\right)$.

\begin{tabular}{ccccc}
\hline Conc., ppm & Temp., ${ }^{\circ} \mathbf{C}$ & $\begin{array}{c}\boldsymbol{C R}, \\
\mathbf{m g} \cdot \mathbf{c m}^{-\mathbf{2}} \cdot \mathbf{m i n}^{-\mathbf{1}}\end{array}$ & $\boldsymbol{\theta}$ & $\boldsymbol{\%} \boldsymbol{I E}$ \\
\hline \multirow{3}{*}{50} & 25 & 0.0252 & 0.772 & 77.2 \\
& 30 & 0.0291 & 0.753 & 75.3 \\
& 35 & 0.0333 & 0.721 & 72.1 \\
& 40 & 0.0291 & 0.701 & 70.1 \\
\hline \multirow{2}{*}{100} & 25 & 0.0201 & 0.791 & 79.1 \\
& 30 & 0.0361 & 0.775 & 77.5 \\
& 35 & 0.0277 & 0.754 & 75.4 \\
& 40 & 0.0331 & 0.714 & 71.1 \\
\hline
\end{tabular}




\begin{tabular}{|c|c|c|c|c|}
\hline Conc., ppm & Temp., ${ }^{\circ} \mathrm{C}$ & $\begin{array}{c}C R, \\
\mathrm{mg} \cdot \mathrm{cm}^{-2} \cdot \mathrm{min}^{-1}\end{array}$ & $\boldsymbol{\theta}$ & $\% I E$ \\
\hline \multirow{4}{*}{150} & 25 & 0.018 & 0.811 & 25 \\
\hline & 30 & 0.0208 & 0.805 & 30 \\
\hline & 35 & 0.0250 & 0.782 & 35 \\
\hline & 40 & 0.0277 & 0.736 & 40 \\
\hline \multirow{4}{*}{200} & 25 & 0.0166 & 0.831 & 25 \\
\hline & 30 & 0.0194 & 0.811 & 30 \\
\hline & 35 & 0.0201 & 0.802 & 35 \\
\hline & 40 & 0.0254 & 0.751 & 40 \\
\hline \multirow{4}{*}{250} & 25 & 0.0138 & 0.855 & 25 \\
\hline & 30 & 0.0212 & 0.831 & 30 \\
\hline & 35 & 0.0236 & 0.821 & 35 \\
\hline & 40 & 0.0277 & 0.781 & 40 \\
\hline \multirow{4}{*}{300} & 25 & 0.0125 & 0.897 & 25 \\
\hline & 30 & 0.0205 & 0.878 & 30 \\
\hline & 35 & 0.0263 & 0.855 & 35 \\
\hline & 40 & 0.0273 & 0.827 & 40 \\
\hline
\end{tabular}

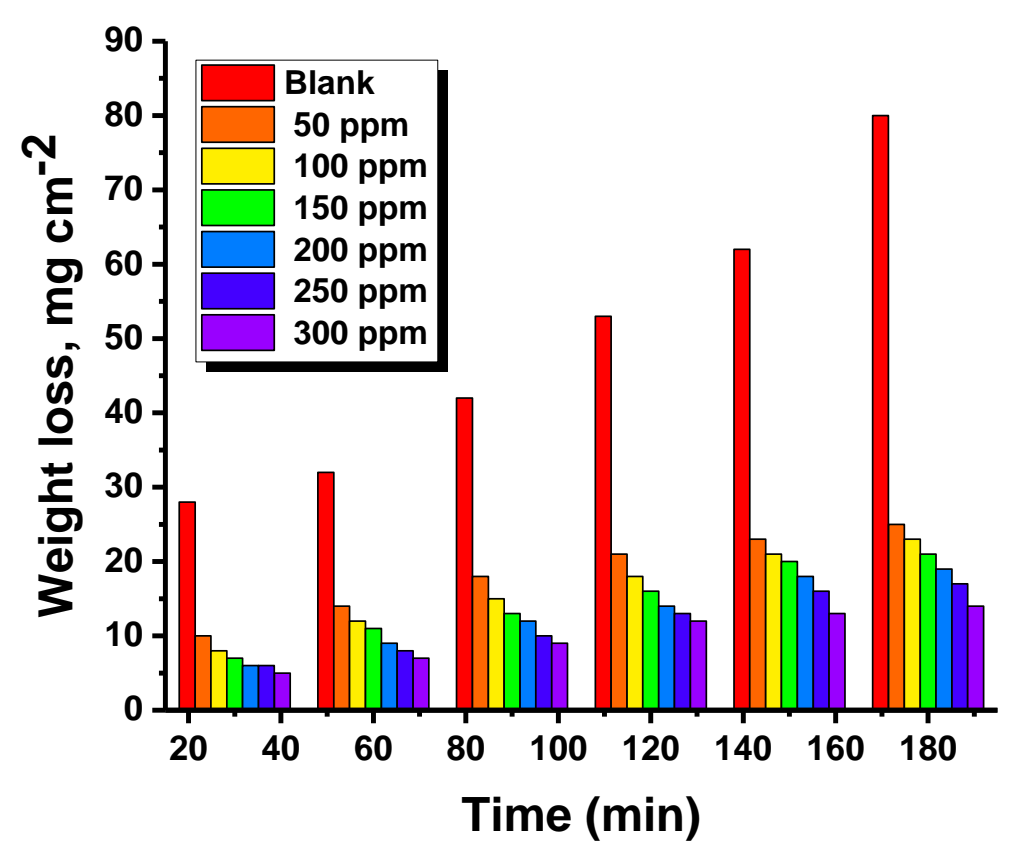

Figure 1. The effect of ML against time for different doses from Morus Alba extract on $\mathrm{Cu}$ corrosion. 


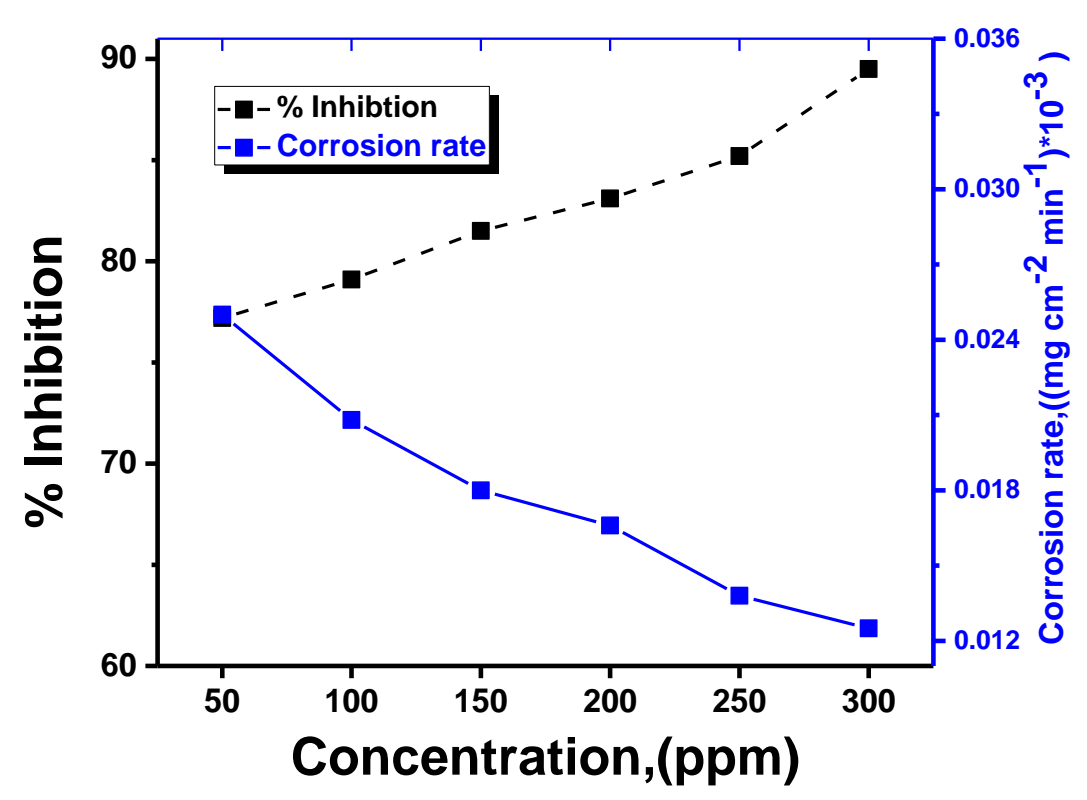

Figure 2. The effect of addition of different doses from Morus Alba extract on the \% IE of $\mathrm{Cu}$ dissolution.

\section{Influence of temperature}

In this examination, the effect of temperature on the corrosion of $\mathrm{Cu}$ pieces used in the investigation and dipped in $2 \mathrm{M}$ of nitric acid was studied in the absence and presence of different doses of Morus Alba extract. It has been found that the $k_{\text {corr }}$ increases with increasing temperature. On the contrary, increasing the doses, reduces the corrosion rate $\left(k_{\text {corr }}\right)$ at one temperature, thus increasing the rate of \%IE. Table 2 shows the effect of temperatures on activation parameters without and in the presence of Morus Alba extract in the temperature range used. The Table shows the $\mathrm{Cu}$ activation energy $\left(E_{\mathrm{a}}^{*}\right)$ calculated from the slope of the graph using the Arrhenius formula:

$$
\log k_{\text {corr }}=\log A-E_{\mathrm{a}}^{*} / 2.303 R T
$$

The universal gas constant was expressed using the symbol $R$, while the symbol $(A)$ was used for the term exponential factor of Arrhenius, and as usual is used to express absolute temperatures [23]. Arrhenius diagrams are illustrated in Figure $3\left[\log \left(k_{\text {corr }}\right)\right.$ against $\left.1000 / T\right]$, in which the energy of the activation is derived from the slopes of straight lines $\left[-E_{\mathrm{a}}^{*} / 2.303 R T\right]$. Using the transitional state equation, the changes in entropy and enthalpy of activation were calculated.

$$
\log \left(k_{\text {corr }} / T\right)=\left[\log (R / N h)+\Delta S_{\mathrm{a}}^{*} / 2.303 R\right]-\Delta H_{\mathrm{a}}^{*} / 2.303 R T
$$

where $(h)$ affords Planck's constant and character $(N)$ is the Avogadro number.

Figure 4 shows straight lines resulting from the plot of $\log \left(k_{\text {corr }} / T\right)$ against $1000 / T$, where this Figure shows the transitional state of the Morus Alba extract. Slopes extracted 
from the shape are used to calculate enthalpy $\left(-\Delta H_{\mathrm{a}}^{*} / 2.303 R T\right)$, and the activation entropy is calculated using the intersections of the lines $\left[\log (R / N h)+\Delta S_{\mathrm{a}}^{*} / 2.303 R\right]$.

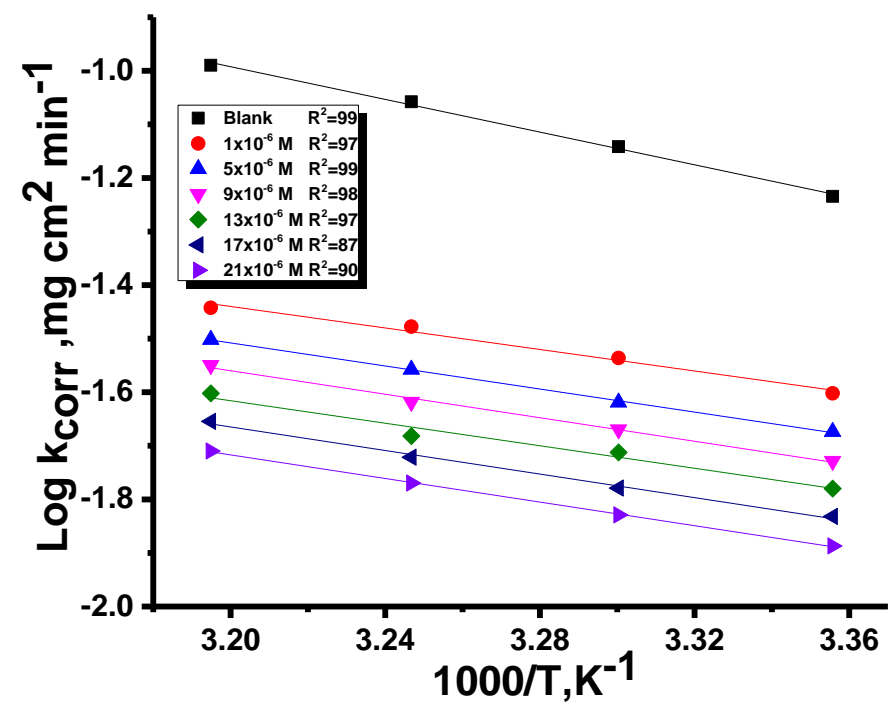

Figure 3. Arrhenius plots (log $\left.k_{\mathrm{corr}} v s .1000 / T\right)$ for $\mathrm{Cu}$ in $2 \mathrm{M}$ nitric acid without and with changed doses of Morus Alba extract.

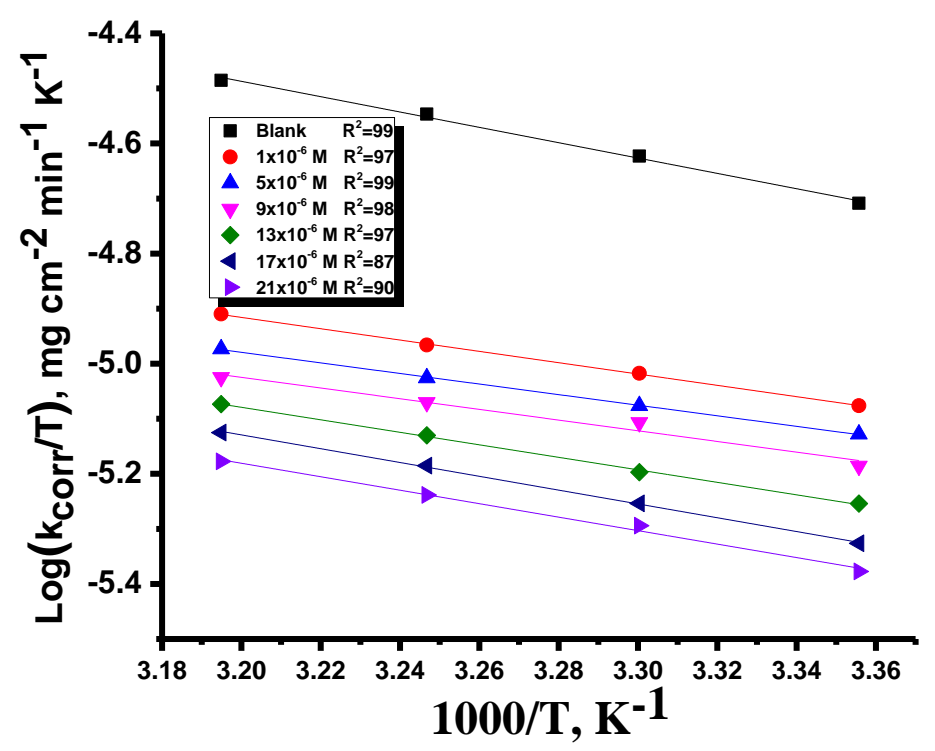

Figure 4. Plots of $\log k_{\mathrm{corr}} / T$ vs. $1000 / T$ for $\mathrm{Cu}$ in $2 \mathrm{M}$ nitric acid without and with altered doses of Morus Alba extract at $25^{\circ} \mathrm{C}$.

Analysis of the results is shown in Table 2. From this Table there is an increase in the activation energy by increasing the dose of Morus Alba extract. This increase is due to the adsorption nature of Morus Alba extract on the $\mathrm{Cu}$ surface and corresponds to the physical adsorption of the components of Morus Alba extract. The results in Table 2 also showed that entropy values are negative in the presence of Morus Alba extract and these negative values 
show that the activated complex in the rate-determining step replaces the dissociation step with the association step. We conclude from this that the initial condition was less arranged than that found in the active molecules of Morus Alba extract. The values of the enthalpy are negative, which in turn indicates that the reaction that occur in the dissolution process is exothermic and it is known that they can be applied to chemical adsorption and physical adsorption [24].

Table 2. Kinetics parameters of Arrhenius equation and transition state equation.

\begin{tabular}{ccccc}
\hline Compound & Conc. ppm & $\begin{array}{c}-\boldsymbol{E}_{\mathbf{a}}^{*} \\
\mathbf{k J} \cdot \mathbf{m o l} \mathbf{l}^{\mathbf{1}}\end{array}$ & $\begin{array}{c}\Delta \boldsymbol{H}^{*} \\
\mathbf{k J} \cdot \mathbf{m o l} \mathbf{l}^{\mathbf{1}}\end{array}$ & $\begin{array}{c}-\Delta \boldsymbol{S}^{*} \\
\mathbf{J} \cdot \mathbf{m o l}^{\mathbf{- 1}} \cdot \mathbf{K}^{\mathbf{- 1}}\end{array}$ \\
\hline Blank & $2 \mathrm{M} \mathrm{HNO}_{3}$ & 42.2 & 14.1 & 167.8 \\
\hline \multirow{2}{*}{ Morus Alba } & 50 & 58.3 & 21.4 & 139.4 \\
& 100 & 63.8 & 22.1 & 135.2 \\
& 150 & 69.1 & 233 & 126.3 \\
& 200 & 71.4 & 25.2 & 123.8 \\
& 250 & 78.8 & 25.7 & 122.3 \\
& 300 & 85.2 & 26.6 & 120.9 \\
\hline
\end{tabular}

\section{Adsorption isotherm}

Isotherms provide significant information for understanding the nature of the corrosion inhibition process. The best fit was found using the Flory-Huggins isotherm. This adsorption isotherm is described by the following equation Eq. (8) [24]:

$$
\log \theta / C=\log x \cdot K_{\text {ads }}+x \cdot \log (1-\theta)
$$

Where $K_{\text {ads }}$ is the equilibrium constant of adsorption process and $C$ is the dose of inhibitor and $\theta$ is the fraction of surface coverage and $x$ is the number of active sites occupied by one molecule or number of water molecules changed by one molecule of the Morus Alba. Drawn of $\log \theta / C v s . \log (1-\theta)$ for adsorbed Morus Alba on the surface of copper in $2 \mathrm{M} \mathrm{HNO}_{3}$ acid at altered temperatures are displayed in Figure 5. The data gave straight lines with maximum value of correlation coefficient indication that Flory-Huggins isotherm is valid for these systems. The $\Delta G_{\text {ads }}^{0}$ of the adsorption process was calculated from the following expression (9):

$$
\Delta G_{\mathrm{ads}}^{0}=-R T \ln \left(55.5 \cdot K_{\mathrm{ads}}\right)
$$

The value 55.5 reveals the amount of water expressed in mol/L in the bulk solution. Table 3 shows the adsorption parameters obtained for Morus Alba. The data in the table confirm the spontaneous adsorption of Morus Alba extract on the copper alloy surface, through the negative $\Delta G_{\text {ads }}^{0}$ values obtained, whose negative value lowered with raising 
temperature, which confirms that the adsorbed layer is more stable at low temperatures. The value of $\Delta G_{\text {ads }}^{0}$ are less than $20 \mathrm{~kJ} / \mathrm{mol}$ are physical adsorption and this resembles to the results obtained [24]. Using the following equation, the change of the standard adsorption enthalpy was determined $\left(-\Delta H_{\text {ads }}^{0}\right)$ and the entropy value was specified $\left(-\Delta S_{\text {ads }}^{0}\right)$ :

$$
\Delta G_{\mathrm{ads}}^{0}=\Delta H_{\mathrm{ads}}^{0}-T \Delta S_{\mathrm{ads}}^{0}
$$

And this by plotting $\Delta G_{\text {ads }}^{0}$ versus $T$ to obtain these values $\left(\left(\Delta H_{\mathrm{ads}}^{0}\right)\right.$ from intercept and $\Delta S_{\text {ads }}^{0}$ obtain from the slope) Figure 6. The value of $\left(\Delta H_{\text {ads }}^{0}\right)$ is negative, which means that adsorption molecules of Morus Alba are exothermic. The exothermic process can refer to physical or chemical adsorption, but the value determines the type of adsorption [25]. Note that the enthalpy values are less than $100 \mathrm{~kJ} / \mathrm{mol}$, indicating that the adsorption is chiefly physical adsorption.

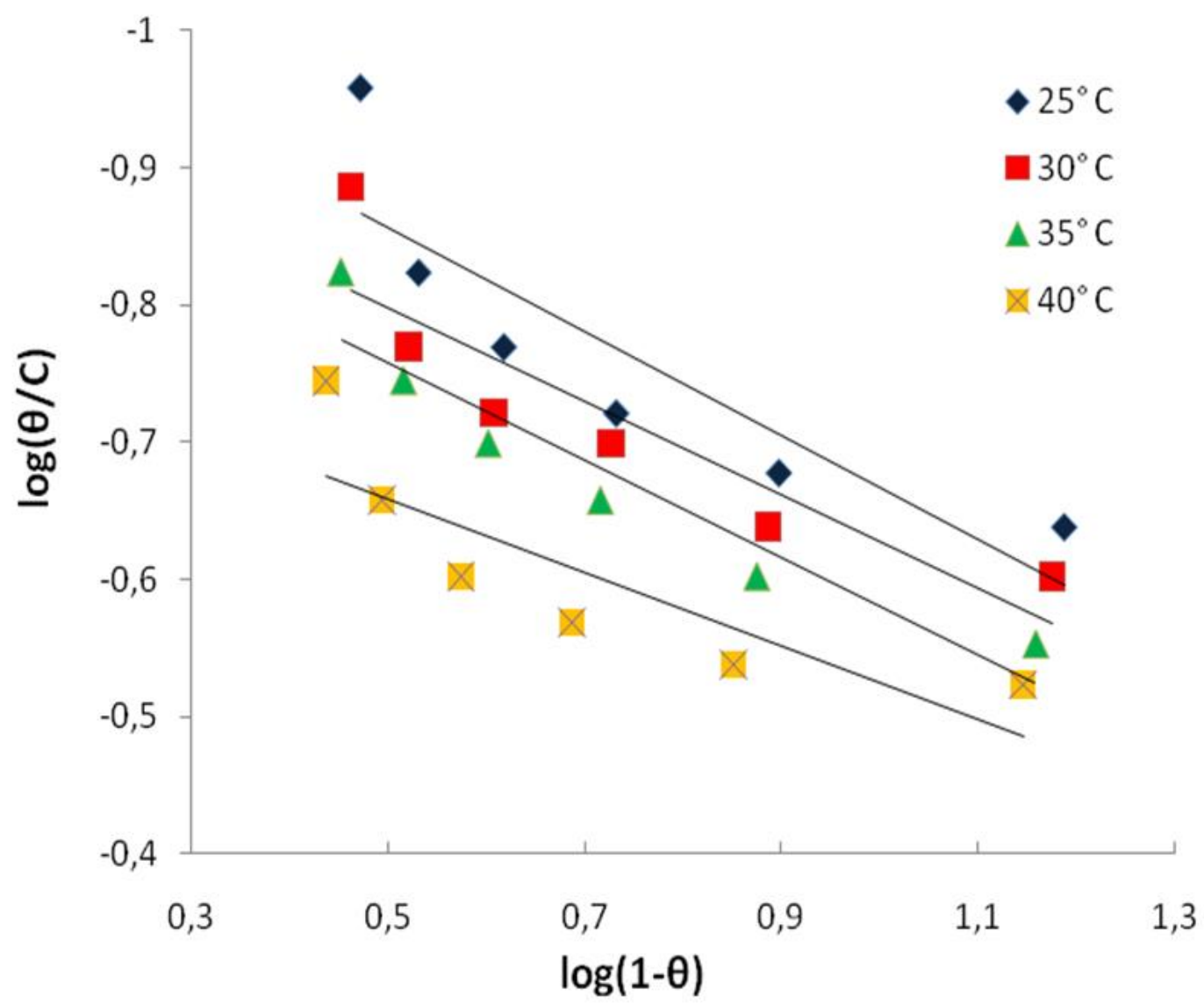

Figure 5. Flory-Huggins adsorption isotherm plotted as $\log (\theta / C)$ vs. $\log (1-\theta)$ of Morus Alba for dissolution of $\mathrm{Cu}$ in $2 \mathrm{M} \mathrm{HNO}_{3}$ solution. 


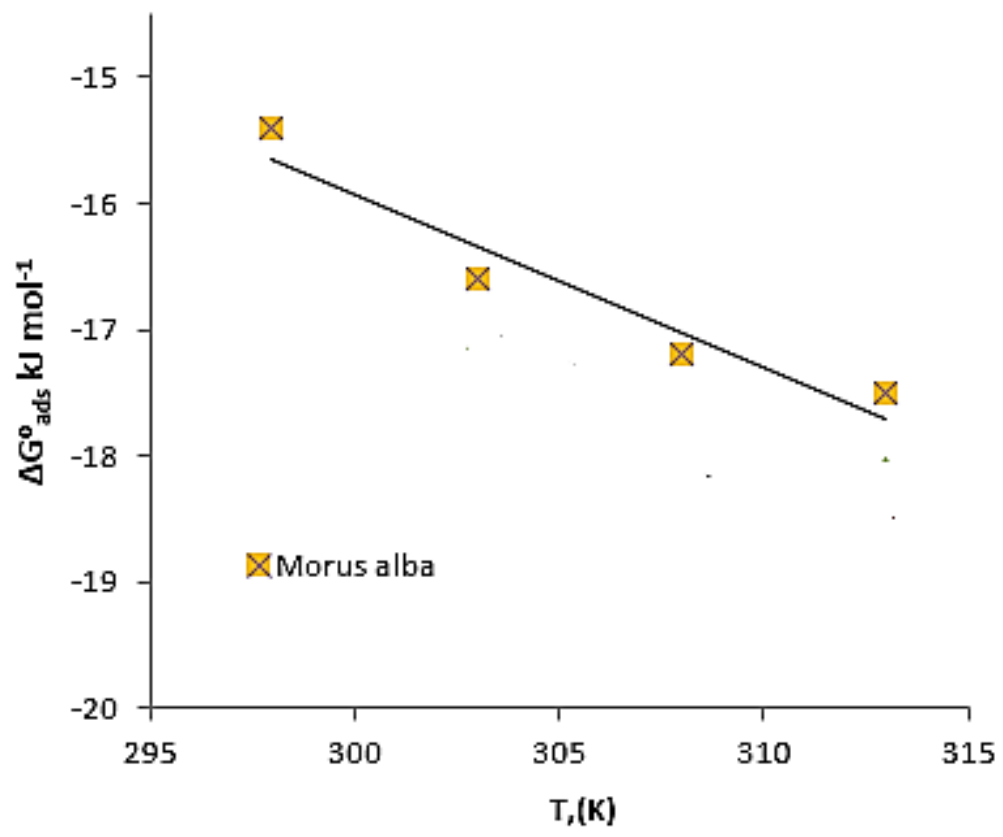

Figure 6. Plot of $\Delta G_{\text {ads }}^{0}$ against $T(\mathrm{~K})$ for Morus Alba extracts.

Table 3. Parameters of Flory-Huggins adsorption for adsorption of Morus Alba on the Cu surface at various temperatures.

\begin{tabular}{cccccc}
\hline Extract & $\begin{array}{c}\text { Temp. } \\
{ }^{\circ} \mathbf{C}\end{array}$ & $\begin{array}{c}\boldsymbol{K}_{\text {ads }} \\
\mathbf{M}^{-\mathbf{1}}\end{array}$ & $\begin{array}{c}-\Delta \boldsymbol{G}_{\text {ads }}^{\mathbf{0}} \\
\mathbf{k J} \cdot \mathbf{m o l}^{\mathbf{1}}\end{array}$ & $\begin{array}{c}-\Delta \boldsymbol{H}_{\text {ads }}^{\mathbf{0}} \\
\mathbf{k J} \cdot \mathbf{m o l}^{\mathbf{- 1}}\end{array}$ & $\begin{array}{c}\Delta \boldsymbol{S}_{\text {ads }}^{\mathbf{0}} \\
\mathbf{J} \cdot \mathbf{m o l}^{-\mathbf{1}} \mathbf{K}^{-\mathbf{1}}\end{array}$ \\
\hline \multirow{3}{*}{ Morus Alba } & 25 & 15.4 & 15.4 & & \\
& 30 & 18.2 & 16.5 & & \\
& 35 & 20.7 & 17.2 & 26 & \\
& 40 & 23.6 & 17.5 & & \\
\hline
\end{tabular}

\section{PP technique}

PP curves in the absence and presence of Morus Alba extract for $\mathrm{Cu}$ in $2 \mathrm{M} \mathrm{HNO}_{3}$ were shown in the Figure 7. It is apparent that the examined extract supports the retardation of $\mathrm{Cu}$ anodic dissolution and discharge reactions of cathodic. PP parameters like corrosion potential $\left(E_{\text {corr }}\right)$, corrosion current density $\left(i_{\text {corr }}\right), \theta$, and $\% I E$ were calculated and tabulated in Table 4. It is noted that because of the adsorption of extract components on the $\mathrm{Cu}$ surface, the Morus Alba extract minimize $i_{\text {corr }}$, while $E_{\text {corr }}$, does not change in the inhibited solutions considerably compared with the uninhibited one. Adding the Morus Alba extract analyzed did not induce a major change in value of $E_{\text {corr }}$, indicates that the inhibitor is of mixed type [26]. It can see from the experimental results that in all cases, addition of inhibitors induced a significant decrease in cathodic and anodic currents. The values of $E_{\text {corr }}$ were affected and slightly shifted to more negative direction by the addition of inhibitors. The lower values of 
$i_{\text {corr }}$ in the presence of investigated extract without causing significant changes in $E_{\text {corr }}$ values and suggest that Morus Alba extract is mixed type.

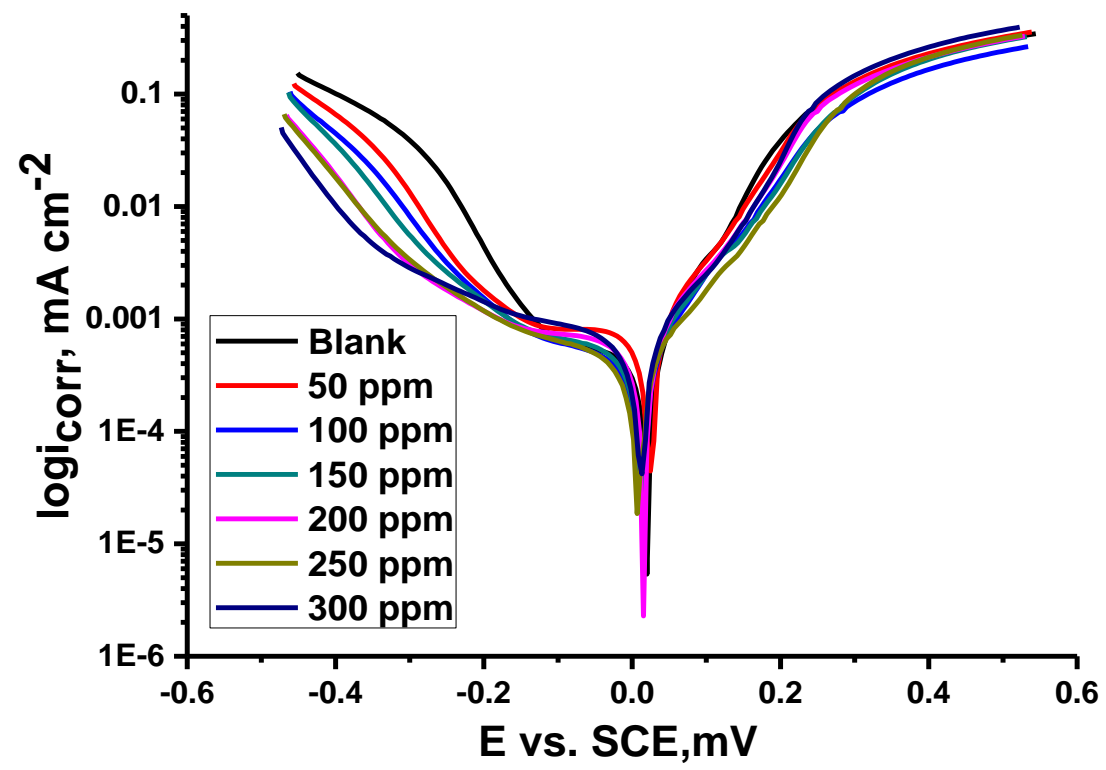

Figure 7. Anodic and cathodic $\mathrm{PP}$ curves for $\mathrm{Cu}$ in $2 \mathrm{M} \mathrm{HNO}_{3}$ in the absence and attendance of various doses of Morus Alba extract.

Table 4. Corrosion parameters obtained from $\mathrm{PP}$ of copper in $2 \mathrm{M} \mathrm{HNO}_{3}$ containing various doses of Morus Alba extracts at $25^{\circ} \mathrm{C}$.

\begin{tabular}{cccccc}
\hline $\begin{array}{c}\text { Conc., } \\
\mathbf{p p m}\end{array}$ & $\begin{array}{c}-\underline{\boldsymbol{E}}_{\text {corr, }}, \\
\mathbf{m V} \boldsymbol{v} \boldsymbol{S} \mathbf{S C E}\end{array}$ & $\begin{array}{c}\boldsymbol{i}_{\text {corr }}, \\
\boldsymbol{\mu A} \cdot \mathbf{c m}^{-\mathbf{2}}\end{array}$ & $\begin{array}{c}\boldsymbol{k}_{\text {corr }}, \\
\mathbf{m m} \cdot \mathbf{y}^{\mathbf{- 1}}\end{array}$ & $\boldsymbol{\theta}$ & $\boldsymbol{\%} \boldsymbol{I E}$ \\
\hline Blank & 45.2 & 342.0 & 41.2 & - & - \\
50 & 43.4 & 88.6 & 33.2 & 0.740 & 74.0 \\
100 & 40.2 & 51.6 & 30.1 & 0.849 & 84.9 \\
150 & 35.35 & 42.6 & 27.2 & 0.875 & 87.5 \\
200 & 32.8 & 31.9 & 22.3 & 0.906 & 80.6 \\
250 & 25.1 & 27.8 & 16.2 & 0.918 & 91.8 \\
300 & 21.2 & 22.3 & 12.1 & 0.934 & 93.4 \\
\hline
\end{tabular}

\section{EIS technique}

Nyquist bends gotten from the copper at potentials after 30 min dipping in $2.0 \mathrm{M} \mathrm{HNO}_{3}$ in the addition and non-addition of different dose of Morus Alba extract. The achieved Nyquist and Bode that are drowning in diagrams for Morus Alba extract are displayed in Figure $(8,9)$. Nyquist diagrams are designated by a semicircle loop. These establish that a charge transfer procedure refers to the dissolution of copper alloy metal [27]. The matching circuit that defines for copper alloy and electrolyte are establish in Figure 10. Table 5 contains different 
parameters, including solution resistance $\left(R_{\mathrm{S}}\right)$, double layer capacitance $\left(C_{\mathrm{dl}}\right)$, charge transfer resistance $\left(R_{\mathrm{ct}}\right),(\Theta)$ and $(\% I E)$ obtained from EIS test. It is notice that the $\left(R_{\mathrm{ct}}\right)$ values increase while the $\left(C_{\mathrm{dl}}\right)$ values gradually decrease as dose of the extract increases; this can be demonstrated by the incremental substitution of water molecules by the extract molecules that adsorbed on the metal surface, results in reduction of the metal dissolution reaction. The results gained in the impedance coefficients for copper alloy in $2 \mathrm{M}$ nitric acid in the presence and absence of altered doses of Morus Alba extract. The radius of the circle rises when the dose of the Morus Alba extract increases and hence, the charge transfer resistance in corrosion reactions rises. From all the above, there is high resistance established as the result of adsorption of the Morus Alba extract at the interface $\mathrm{Cu}$ /solution. The interfacial capacitance $C_{\mathrm{dl}}$ data can be estimated from CPE parameter $\left(Y_{0}\right.$ and $\left.n\right)$ is defined in next Eq. (11):

$$
C_{\mathrm{dl}}=Y_{0} \cdot\left(\omega_{\max }\right)^{n-1}
$$

Where, $Y_{0}$ is the CPE magnitude, and $n$ is the variance CPE data of the: $-1<n<1$. From Table 5 we note a lower in the data of $C_{\mathrm{dl}}$ with an increment in the dose of Morus Alba extract, and a lower in the local dielectric constant and/or rises in the thickness of the electrical double layer [28] can explain this. This due to the adsorption of Morus Alba molecules on the $\mathrm{Cu}$ /interface of solution and forming of a protective film on the interface of the $\mathrm{Cu}$ solution. Table 5 lists the values of parameters like $R_{\mathrm{s}}, R_{\mathrm{ct}}$, by EIS fitting as well as the derived parameters $C_{\mathrm{dl}}$ and $I E \%$.

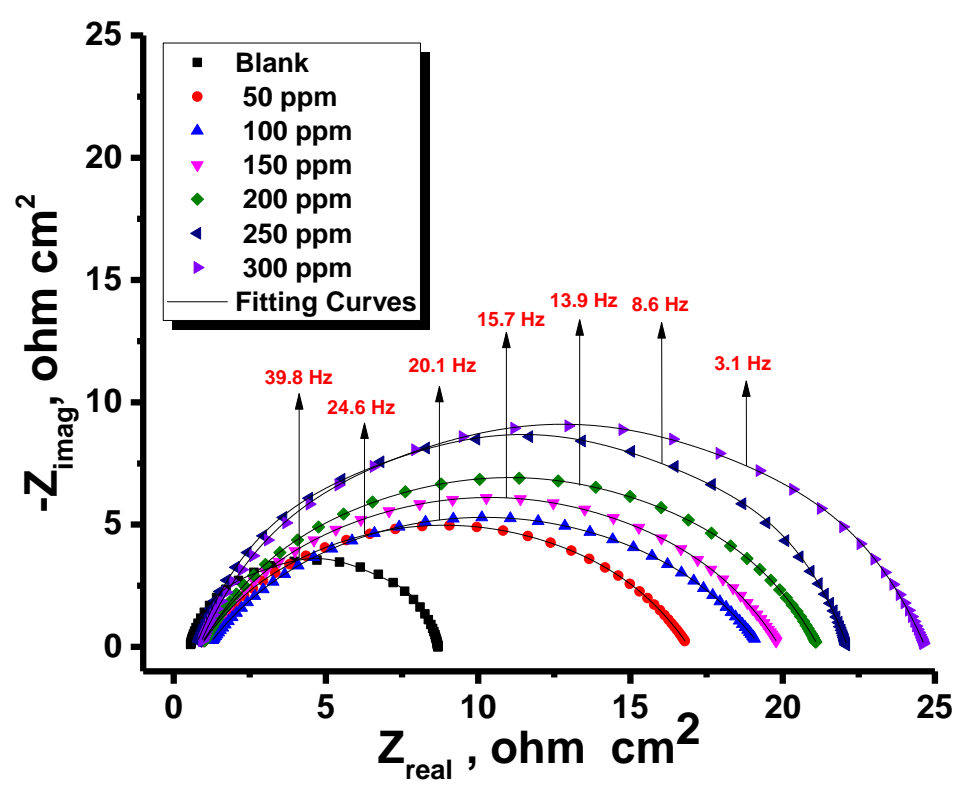

Figure 8. The Nyquist plots for dissolution of copper in $2 \mathrm{M} \mathrm{HNO}_{3}$ in the presence and in the absence of different doses of Morus Alba extract at $25^{\circ} \mathrm{C}$. 


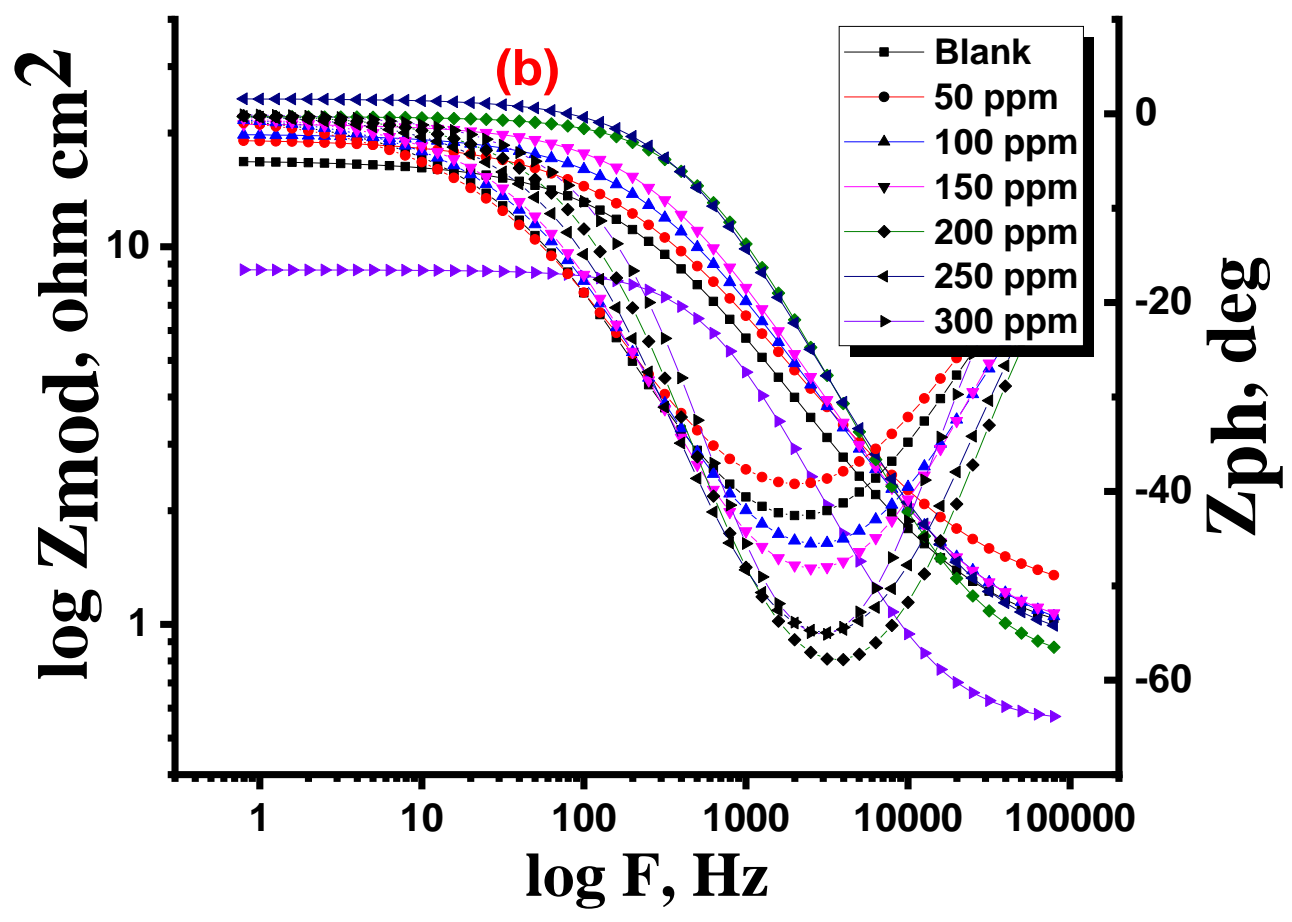

Figure 9. The Bode plots for dissolution of copper in $2 \mathrm{M} \mathrm{HNO}_{3}$ in the presence and absence of different doses of Morus Alba extract at $25^{\circ} \mathrm{C}$.

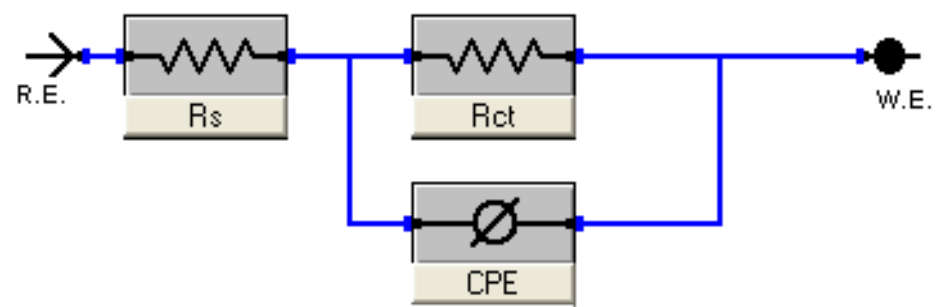

Figure 10. Equivalent model circuit utilized to fit experimental EIS data.

Table 5. EIS data for $\mathrm{Cu}$ in $2 \mathrm{M} \mathrm{HNO}_{3}$ without and with various doses of Morus Alba extracts at $25^{\circ} \mathrm{C}$.

\begin{tabular}{cccccc}
$\begin{array}{c}\text { Conc. } \\
\mathbf{p p m}\end{array}$ & $\begin{array}{c}\boldsymbol{R}_{\mathbf{s}} \\
\mathbf{\Omega} \mathbf{c m}^{\mathbf{2}}\end{array}$ & $\begin{array}{c}\boldsymbol{R}_{\mathbf{c t}} \\
\mathbf{\Omega} \cdot \mathbf{c m}^{\mathbf{2}}\end{array}$ & $\begin{array}{c}\boldsymbol{C}_{\mathbf{d l}} \\
\mathbf{F} \cdot \mathbf{c m}^{-2}\end{array}$ & $\boldsymbol{\theta}$ & $\boldsymbol{\%} \boldsymbol{E}$ \\
\hline $2 \mathrm{M} \mathrm{HNO}_{3}$ & 1.280 & 119 & 653.2 & - & - \\
50 & 1.190 & 172 & 628.5 & 0.516 & 51.6 \\
100 & 0.963 & 193 & 613.9 & 0.633 & 63.3 \\
150 & 0.941 & 224 & 599.1 & 0.721 & 72.1 \\
200 & 0.855 & 289 & 561.3 & 0.824 & 82.4 \\
250 & 0.897 & 305 & 541.6 & 0.896 & 89.6 \\
300 & 0.890 & 362 & 488.3 & 0.932 & 93.2 \\
\hline
\end{tabular}




\section{Electrochemical Frequency Modulation (EFM) technique}

Intermodulation spectra of copper in in the acid corrosive medium without and with different doses of Morus Alba at $25^{\circ} \mathrm{C}$ were shown in Figure 11. The bigger peaks were utilized to compute $i_{\text {corr }}$, and the causality factors (CF-2 \& CF-3). Parameters gotten from EFM procedures were recorded in Table 6 . The decrease in $i_{\text {corr }}$ with the increase in Morus Alba dose results in a decrease in $C R$ and increase in $\Theta$ \& \%IE. The near values of CF- 2 \& CF-3 from theoretical values (2.0 and 3.0) reinforce the validity of Tafel slopes and $i_{\text {corr }}$, this accords with the EFM theory [29].
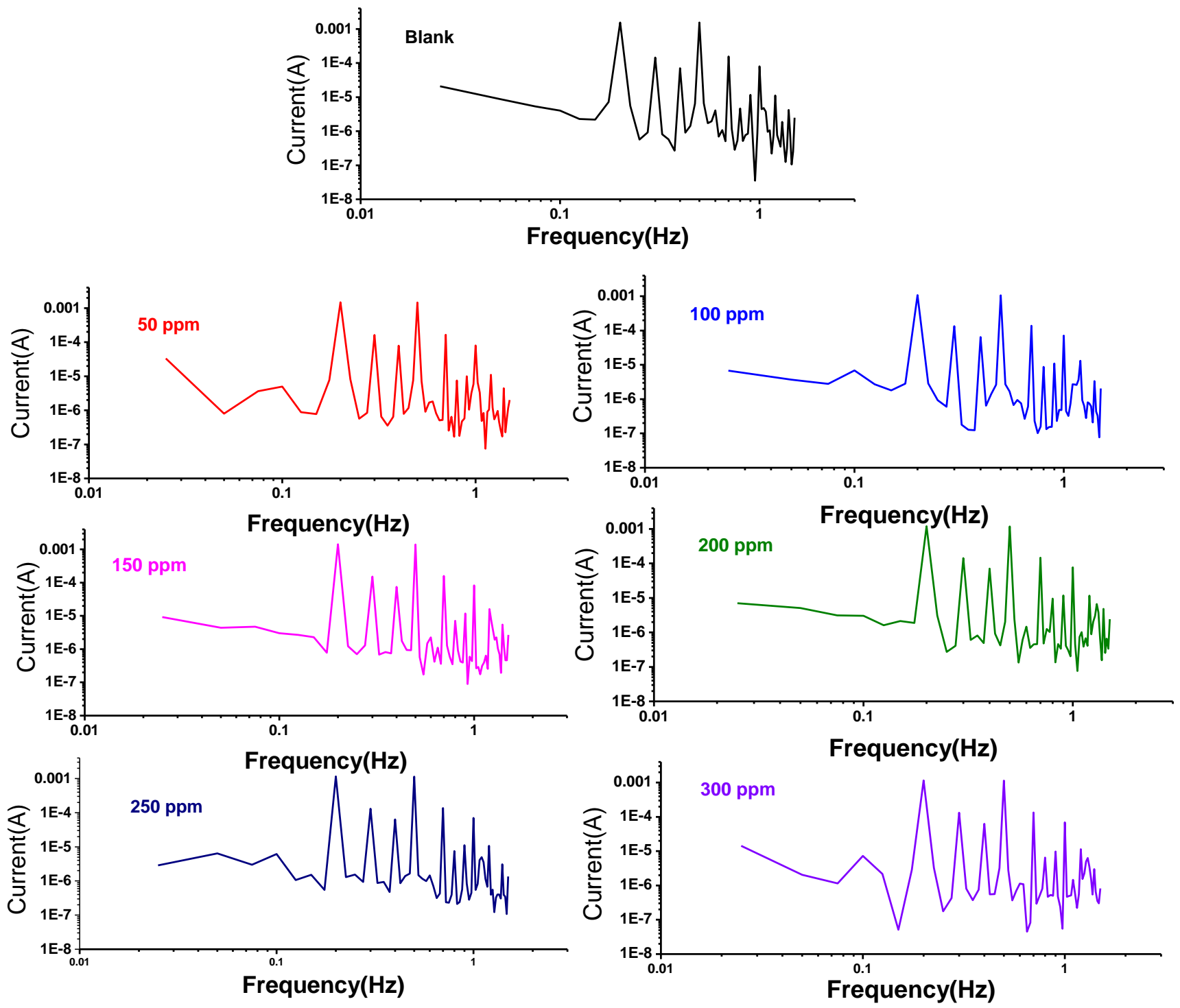

Figure 11. EFM spectra for copper in the acid corrosive medium without and with altered doses of Morus Alba at $25^{\circ} \mathrm{C}$ 
Table 6. The parameters gained from EFM procedures for $\mathrm{Cu}$ in the acid corrosive medium without and with altered doses of Morus Alba at $25^{\circ} \mathrm{C}$.

\begin{tabular}{ccccccc}
\hline $\begin{array}{c}\text { Conc., } \\
\mathbf{p p m}\end{array}$ & $\begin{array}{c}\boldsymbol{i}_{\text {corr, }}, \\
\boldsymbol{\mu} \mathbf{A} \cdot \mathbf{c m}^{-2}\end{array}$ & $\begin{array}{c}\boldsymbol{k}_{\text {corr, }} \\
\mathbf{m p y}\end{array}$ & $\mathbf{C F - 2}$ & $\mathbf{C F - 3}$ & $\boldsymbol{\theta}$ & $\boldsymbol{\%} \boldsymbol{E}$ \\
\hline $2 \mathrm{M} \mathrm{HNO}_{3}$ & 225.3 & 147.5 & 1.94 & 2.991 & - & - \\
50 & 112.2 & 80.2 & 1.92 & 3.54 & 0.501 & 50.1 \\
100 & 98.6 & 66.4 & 1.88 & 3.96 & 0.562 & 56.2 \\
150 & 82.5 & 49.5 & 2.02 & 2.81 & 0.633 & 63.3 \\
200 & 77.1 & 35.6 & 1.96 & 2.96 & 0.657 & 65.7 \\
250 & 62.5 & 27.7 & 1.81 & 3.02 & 0.722 & 72.2 \\
300 & 33.4 & 11.9 & 1.77 & 2.76 & 0.851 & 85.1 \\
\hline
\end{tabular}

Scanning Electron Microscopy (SEM) Studies

Scanning electron microscopic images for the blank of the copper specimens before and after $12 \mathrm{~h}$ exposure in the $2 \mathrm{M} \mathrm{HNO}_{3}$ medium in the lack and attendance of Morus Alba are given in Figure 12. Figure 12a referred to $\mathrm{Cu}$ coins after dipping in nitric acid (blank) and Figure $12 \mathrm{~b}$ is an image gotten from the $\mathrm{Cu}$ coins after dipping in the test solution for Whereas in the attendance of the optimum dose of the Morus Alba, the $\mathrm{Cu}$ is hindrance and thus the smooth surface evidences there are Morus Alba extract molecules are adsorbed on the top surface incorporating into the passive film in order to block the active site present on the $\mathrm{Cu}$ metal surface [30].

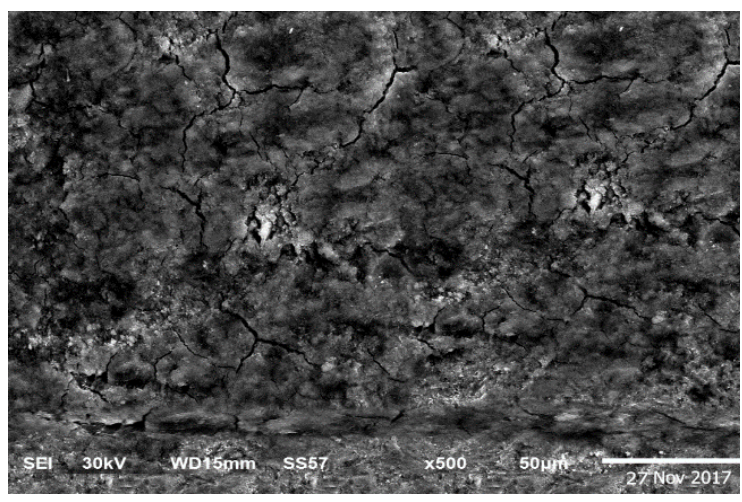

(a)

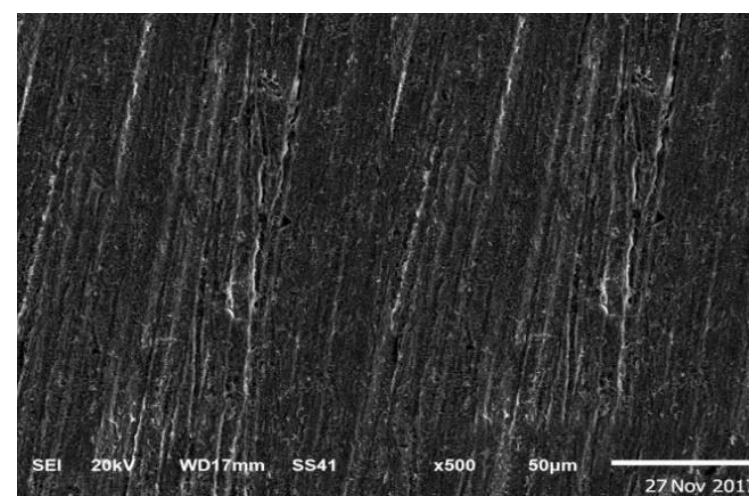

(b)

Figure 12. SEM image gotten from the dipping of $\mathrm{Cu}$ coins in $2 \mathrm{M} \mathrm{HNO}_{3}$ without Morus Alba (a) and $\mathrm{Cu}$ after dipping of $2 \mathrm{M} \mathrm{HNO}_{3}+300$ ppm of Morus Alba for $24 \mathrm{~h}$ (b).

Atomic force microscopy (AFM) analysis

Figure 13 illustrates three-dimensional AFM images of $\mathrm{Cu}$ surface without the extract (Figure 13a) and with $300 \mathrm{ppm}$ Morus Alba extract (Figure 13b). In uninhibited system, the $\mathrm{Cu}$ surface was damaged due to dissolution in corrosive medium with roughness of $180 \mathrm{~nm}$. 
The roughness of inhibited $\mathrm{Cu}$ surface was $83 \mathrm{~nm}$ due to formation of a protective layer on the surface which causes the decrease of the surface roughness and effectively protects it from corrosion.

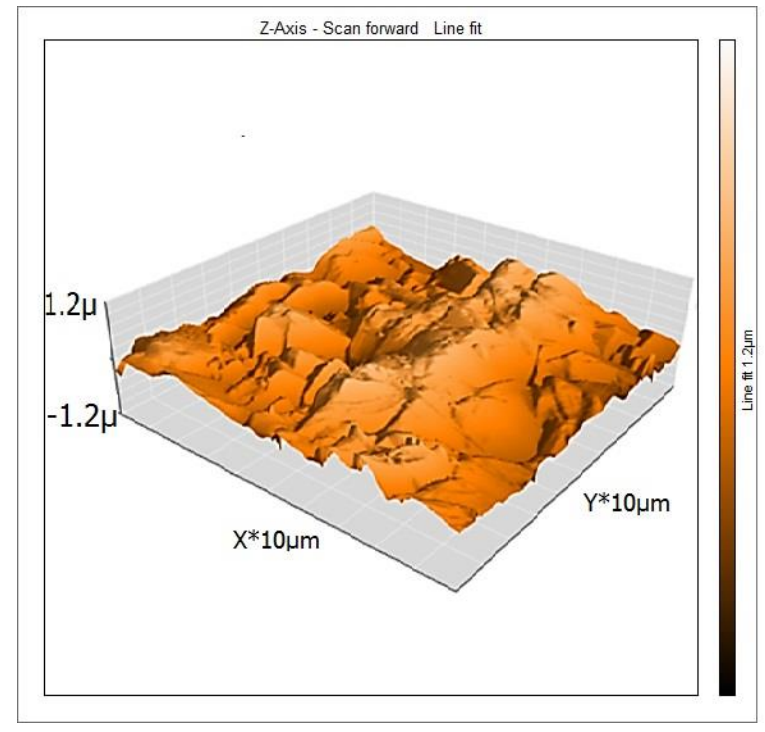

(a)

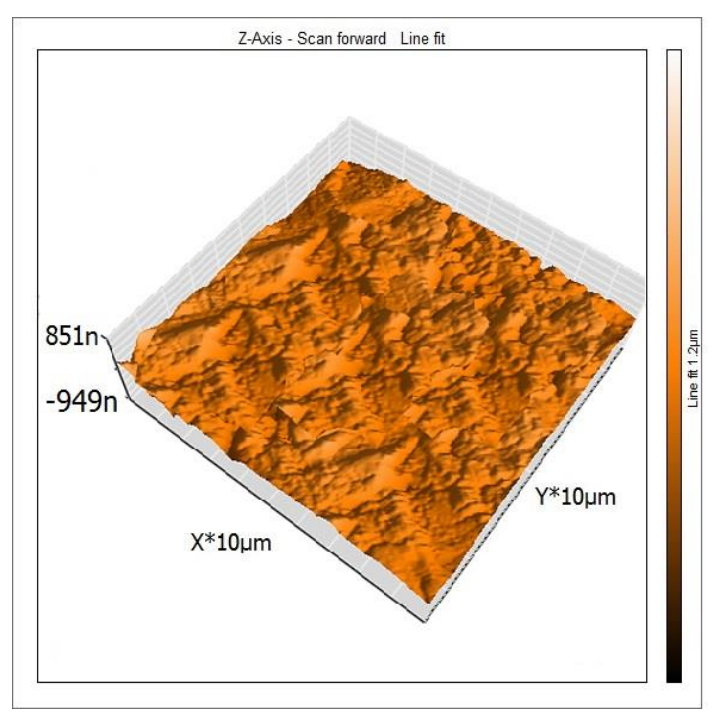

(b)

Figure 13. An image obtained for the immersion of $\mathrm{Cu}$ specimen in $2 \mathrm{M} \mathrm{HNO}_{3}$ without Morus Alba extracts (a) and $\mathrm{Cu}$ sample after dipping of $2 \mathrm{M} \mathrm{HNO}_{3}+300 \mathrm{ppm}$ of Morus Alba extract for $24 h(b)$.

\section{Mechanism of Corrosion Inhibition}

This plant mainly contains anthraquinones, flavonoids, polyphenols lipids and sterols [19]. The adsorption on the copper surface (via the physisorption), in the acid medium indicates that, copper surface bear's positive charge, so it is difficult to the protonated molecules to adsorb on the copper surface due to the electrostatic repulsion. $\mathrm{NO}_{3}^{-}$ions get adsorbed on copper surface generate an extra negative charge near the solution and approval more adsorption for the cations. Owing to the electrons lone pair of $\mathrm{O}$ and $\mathrm{N}$ atoms in Morus Alba molecules or the protonated molecules may association with freshly produced $\mathrm{Cu}^{2+}$ ions on the copper surface forming copper inhibitor complexes. These complexes adsorbed onto the copper by force (Van der Waals) to form protecting cover to prevent copper from corrosion $[31,32]$.

\section{Conclusions}

The examined Morus Alba extract shows high inhibition activity for copper corrosion in solution of $2 \mathrm{M} \mathrm{HNO}_{3}$, and the inhibition was clarified. The adsorption of Morus Alba extract over copper surface obeyed Flory-Huggins adsorption isotherm. The adsorption parameters indicated that adsorption of Morus Alba extract on the copper surface was spontaneous. PP procedures indicate that Morus Alba extract exhibits cathodic and anodic inhibition effects. As Morus Alba extract increases, reduction occurs in $C_{\mathrm{dl}}$, while a raise in 
$R_{\mathrm{ct}}$ was attained with rising the extract dose. AFM results for copper surface with Morus Alba extract indicates low roughness, meaning that the inhibitive film is formed on the surface of the metal. Agreement among these different independent techniques indicates the validity of the obtained results.

\section{References}

1. S. Al-Nami and A.S. Fouda, Corrosion Inhibition Effect and Adsorption Activities of methanolic myrrh extract for $\mathrm{Cu}$ in $2 \mathrm{M} \mathrm{HNO}_{3}$, Int. J. Electrochem. Sci., 2020, 15, $1187-$ 1205. doi: $10.20964 / 2020.02 .23$

2. M.A. Elmorsi and A.M. Hassanein, Corrosion inhibition of copper by heterocyclic compounds, Corros. Sci., 1999, 41, no. 12, 2337-2352. doi: 10.1016/S0010938X(99)00061-X

3. F. Zucchi, V. Grassi, A. Frignani and G. Trabanelli, Inhibition of copper corrosion by silane coatings, Corros. Sci., 2004, 46, no. 11, 2853-2865. doi: 10.1016/j.corsci.2004.03.019

4. L.R. Chauhan and G. Gunasekaran, Corrosion inhibition of mild steel by plant extract in dilute $\mathrm{HCl}$ medium, Corros. Sci., 2007, 49, no. 3, 1143-1161. doi: 10.1016/j.corsci.2006.08.012

5. F.S. de Souza, C. Giacomelli, R.S. Gonçalves and A. Spinelli, Adsorption behavior of caffeine as a green corrosion inhibitor for copper, Mater. Sci. Eng.: C, 2012, 32, no. 8, 2436-2444. doi: 10.1016/j.msec.2012.07.019

6. A.S. Fouda , Y.M. Abdallah, G.Y. Elawady and R.M. Ahmed, Zygophllum coccineum L. Extract as green corrosion inhibitor for copper in $1 \mathrm{M} \mathrm{HNO}_{3}$ Solutions, Int. J. Adv. Res., 2014, 2, no. 11, 517-531.

7. A.S. Fouda, K. Shalabi and A.A. Idress, Ceratonia siliqua extract as a green corrosion inhibitor for copper and brass in nitric acid solutions, Green Chem. Lett. Rev., 2015, 8, no. 3-4, 17-29. doi: 10.1080/17518253.2015.1073797

8. K. Dahmani, M. Galai, M. Ouakki, M. Cherkaoui, R. Touir, S. Erkan, S. Kaya and B. El Ibrahimi, Quantum chemical and molecular dynamic simulation studies for the identification of the extracted cinnamon essential oil constituent responsible for copper corrosion inhibition in acidified $3.0 \mathrm{wt} \% \mathrm{NaCl}$ medium, Inorg. Chem. Commun., 2021, 124, 108409. doi: $10.1016 /$ j.inoche.2020.108409

9. A.S. Fouda, S.M. Abdel Motaal, A.S. Ahmed, H.B. Sallam, A. Ezzat and A. ElHossiany, Corrosion Protection of Carbon Steel in $2 \mathrm{M} \mathrm{HCl}$ Using Aizoon canariense Extract, Biointerface Res. Appl. Chem., 2022, 12, no. 1, 230-243.

10. O.N. Francis, O.O. Israel and E. Osarolube, Acidic Corrosion Inhibition Mechanism of Al Alloy Using Green Inhibitors, Am. J. Mater. Sci., 2018, 8, no. 3, 45-50. doi: 10.5923/j.materials.20180803.01

11. M. Shyamala and A. Arulanantham, A comparative study on the inhibitory action of some green inhibitors on the corrosion of mild steel in nitrric acid medium, Malays. J. Anal. Sci., 2017, 21, no. 2, 346-355. doi: 10.17576/mjas-2017-2102-09 
12. M. Shyamala and P.K. Kasthuri, The Inhibitory Action of the Extracts of Adathoda vasica, Eclipta alba, and Centella Asiatica on the Corrosion of Mild Steel in Nitric Acid Medium: A Comparative Study, Int. J. Corros., 2012, 852827-852835. doi: $10.1155 / 2012 / 852827$

13. A.S. Fouda, N.E. Al-Hazmi, H.H. El-Zehry and A. El-Hossainy, Electrochemical and Surface Characterization of Chondria Macrocarpa Extract (CME) as Save Corrosion Inhibitor for Aluminum in $1 \mathrm{M} \mathrm{HCl} \mathrm{Medium,} \mathrm{J.} \mathrm{Appl.} \mathrm{Chem.} \mathrm{(Lumami,} \mathrm{India),} \mathrm{2020,} 9$, no. 3, 362-381.

14. K.F. Khaled, Evaluation of electrochemical frequency modulation as a new technique for monitoring corrosion and corrosion inhibition of carbon steel in perchloric acid using hydrazine carbodithioic acid derivatives, J. Appl. Electrochem., 2009, 39, no. 3, 429438. doi: $10.1007 / \mathrm{s} 10800-008-9688-\mathrm{y}$

15. O.A. Elgyar, A.M. Ouf, A. El-Hossiany and A.S. Fouda, The Inhibition Action of Viscum Album Extract on the Corrosion of Carbon Steel in Hydrochloric Acid Solution, Biointerface Res. Appl. Chem., 2021, 11, no. 6, 14344-14358.

16. M.A. Deyab, M.M. Osman, A.E. Elkholya and F.E. Heakal, Green approach towards corrosion inhibition of carbon steel in produced oilfield water using lemongrass extract, RSC Adv., 2017, 7, 45241-45251. doi: 10.1039/c7ra07979f

17. A.S. Fouda, E. El-Gharkawy, H. Ramadan and A. El-Hossiany, Corrosion Resistance of Mild Steel in Hydrochloric Acid Solutions by Clinopodium acinos as a Green Inhibitor, Biointerface Res. Appl. Chem., 2021, 11, no. 2, 9786-9803.

18. W. Emori, R.-H. Zhang, P.C. Okafor, X.W. Zheng, T. He, K. Wei, X.Z. Lin and C.R. Cheng, Adsorption, and corrosion inhibition performance of multiphytoconstituents from Dioscorea septemloba on carbon steel in acidic media: Characterization, experimental and theoretical studies, Colloids Surf., A, 2020, 590, 124534. doi: $10.1016 /$ j.colsurfa.2020.124534

19. T. Katsube, N. Imawaka, Y. Kawano, Y. Yamazaki, K. Shiwaku, and Y. Yamane, Antioxidant flavonol glycosides in mulberry (Morus Alba L.) leaves isolated based on LDL antioxidant activity, Food Chem., 2006, 97, no. 1, 25-31. doi: 10.1016/j.foodchem.2005.03.019

20. A.S. Fouda, R.E. Ahmed and A. El-Hossiany, Chemical, Electrochemical and Quantum Chemical Studies for Famotidine Drug as a Safe Corrosion Inhibitor for $\alpha$-Brass in $\mathrm{HCl}$ Solution, Prot. Met. Phys. Chem. Surf., 2021, 57, no. 2, 398-411. doi: 10.1134/S207020512101010X

21. A.S. Fouda, K. Shalabi and A. El-Hossiany, Moxifloxacin, Antibiotic as green corrosion inhibitor for carbon steel in $1 \mathrm{M} \mathrm{HCl}, \mathrm{J}$. Bio- Tribo-Corros., 2016, 2, no. 18, 1-13. doi: 10.1007/s40735-016-0048-X

22. M.M. Saleh, M.G. Mahmoud and H.M. Abd El-Lateef, Comparative study of synergistic inhibition of mild steel and pure iron by 1-hexadecylpyridinium chloride and bromide ions, Corros. Sci., 2019, 154, 70-79. doi: 10.1016/j.corsci.2019.03.048 
23. A.S. Fouda, M.A. Abd El-Ghaffar, M.H. Sherif, A.T. El-Habab and A. El-Hossiany, Novel anionic 4-tert-octyl phenol ethoxylate phosphate surfactant as corrosion inhibitor for C-steel in acidic media, Prot. Met. Phys. Chem. Surf., 2020, 56, no. 1, 189-201. doi: $10.1134 / \mathrm{S} 2070205120010086$

24. S.H. Kumar and S. Karthikeyan, Inhibition of mild steel corrosion in hydrochloric acid solution by cloxacillin drug, J. Mater. Environ. Sci., 2012, 3, no. 5, 925-934.

25. M.M. Motawea, A. El-Hossiany and A.S. Fouda, Corrosion control of copper in nitric acid solution using Chenopodium extract, Int. J. Electrochem. Sci., 2019, 14, 1372 1387.

26. A.S. Fouda, H. Ibrahim, S. Rashwan, A. El-Hossiany and R.M. Ahmed, Expired drug (pantoprazole sodium) as a corrosion inhibitor for high carbon steel in hydrochloric acid solution, Int. J. Electrochem. Sci., 2018, 13, 6327-6346.

27. A.S. Fouda, M. Eissa and A. El-Hossiany, Ciprofloxacin as eco-friendly corrosion inhibitor for carbon steel in hydrochloric acid solution, Int. J. Electrochem. Sci., 2018, 13, 11096-11112.

28. R.W. Bosch, J. Hubrecht, W.F. Bogaerts and B.C. Syrett, Electrochemical frequency modulation: A new electrochemical technique for online corrosion monitoring, Corrosion, 2001, 57, no. 1, 60-70. doi: 10.5006/1.3290331

29. D.Q. Zhang, Q.R. Cai, X.M. He, I.X. Gao and G.S. Kim, Corrosion inhibition and adsorption behavior of methionine on copper in $\mathrm{HCl}$ and synergistic effect of zinc ions, Mater. Chem. Phys., 2013, 114, 612-617. doi: 10.1016/j.matchemphys.2008.10.007

30. Y. Baymou, H. Bidi, M. Ebn Touhami, M. Allam, M. Rkayae and R.A. Belakhmima, Corrosion Protection for Cast Iron in Sulfamic Acid Solutions and Studies of the Cooperative Effect Between Cationic Surfactant and Acid Counterions, J. Bio- TriboCorros., 2018, 4, 11. doi: 10.1007/s40735-018-0127-2

35. S. Zhang, L. Hou, H. Du, H. Wei, B. Liu and Y. Wei, A study on the interaction between chloride ions and $\mathrm{CO}_{2}$ towards carbon steel corrosion, Corros. Sci., 2020, 167, 108531. doi: $10.1016 /$ j.corsci.2020.108531

31. A.S. Fouda, S.A. Abd El-Maksoud, A. El-Hossiany and A. Ibrahim, Evolution of the Corrosion-inhibiting Efficiency of Novel Hydrazine Derivatives against Corrosion of Stainless Steel 201 in Acidic Medium, Int. J. Electrochem. Sci., 2019, 14, 6045-6064.

32. N. Soltani, N. Tavakkoli, A. Attaran, B. Karimi and M. Khayatkashani, Inhibitory effect of Pistacia khinjuk aerial part extract for carbon steel corrosion in sulfuric acid and hydrochloric acid solutions, Chem. Pap., 2020, 74, 1799-1815. doi: 10.1007/s11696019-01026-y 